\title{
Maternal effects vary between source populations in the Atlantic tomcod Microgadus tomcod
}

\author{
Bridget S. Green $^{1, *}$, R. Christopher Chambers ${ }^{2}$ \\ ${ }^{1}$ Tasmanian Aquaculture and Fisheries Institute Marine Research Laboratories, University of Tasmania, Private Bag 49, \\ Hobart, Tasmania 7001, Australia \\ ${ }^{2}$ NOAA Fisheries Service, Howard Laboratory, 74 Magruder Rd., Highlands, New Jersey 07732, USA
}

\begin{abstract}
Identifying the sources of variation in traits of larvae is one of the first steps in interpreting the role of phenotypic variation in recruitment. We examined the contributions of geographic source and parentage to phenotypic variation in offspring traits in a gadid, Microgadus tomcod, from 2 contrasting yet nearby locations. Adults were collected from the Hudson River (HR), a polluted riverine estuary with strong freshwater and tidal fluxes, and Shinnecock Bay (SB), a relatively clean barrier beach and lagoon system with minimal freshwater inflows. Eggs were stripped from fish in the laboratory and incubated in a common environment. Female and offspring traits varied substantially between populations. Females from SB had a higher ovary weight and gonado-somatic index (GSI) relative to body length, and produced larger eggs. Contrary to expectation, higher female condition did not result in larvae of better condition. SB offspring had smaller yolk reserves at hatch and were less resistant to starvation than offspring from HR, though size at hatching did not differ between the 2 populations. SB offspring took $25 \%$ longer to hatch, thereby increasing dependence on yolk reserves as embryos. This may represent a trade-off in time to hatching versus quality at hatching in tomcod from different environments. Geographic source accounted for more variance than maternal effects in time to hatch $(90 \%)$ and yolk volume at hatch $(42 \%)$. Maternal influence accounted for more variance in egg diameter $(90 \%)$, length at hatch $(33 \%)$ and starvation resistance $(30 \%)$, though none of these measures was correlated to female size or age. These results emphasize differences in early life history traits across a small geographic scale and the extent to which offspring differences due to maternal effects depend on the local environment.
\end{abstract}

KEY WORDS: Geographic variation · Maternal effect · Offspring variation · Phenotypic variation

\section{INTRODUCTION}

Quality in early life history (ELH) traits can be critical to an individual's chances of survival, and, within a population, variations in trait values may lead to recruitment fluctuations (Meekan \& Fortier 1996, Vigliola \& Meekan 2002). Marine fishes typically produce large numbers of relatively poorly provisioned propagules, with a correspondingly low likelihood of surviving the larval stage (Ferron \& Leggett 1994). Furthermore, mortality in the ELH stages can be selective, favouring survival of higher quality larvae (Meekan \& Fortier 1996, Bergenius et al. 2002) and juveniles (Hoey \& McCormick 2004). Understanding sources of variation in traits is the first step to understanding differential and selective survival and its potential impact on recruitment fluctuation. In addition to a possible genetic basis to this phenotypic variance, environmental and non-genetic maternal factors are believed to play important roles.

The relationship between the female parent and the quality of her offspring has recently received much attention (e.g. Chambers \& Leggett 1996, Trippel \& Neil 2004). Maternal effects are broadly defined as non-genetic influences, derived from the maternal phenotype or her environment, that have an impact on offspring phenotypes (Heath \& Blouw 1998). Differences among females can be an important source of 
variation in ELH traits. For example, up to $71 \%$ of within-population variation in egg size, presumed to be of a non-genetic origin, has been attributed to differences among females (Chambers \& Leggett 1996). In wild populations, there is some indication that higher quality offspring (Marteinsdottir \& Steinarrson 1998) and higher numbers of recruits (Wright \& Gibb 2005) come from older and larger females, suggesting that female quality influences larval survival and recruitment.

Environmental variation is also a key cause of phenotypic variation. Environmental variation during the ELH stages can influence larval condition (Green \& McCormick 1999), performance (Green \& Fisher 2004), growth and development (Sponaugle et al. 2006), and ensuing recruitment magnitude (Bergenius et al. 2005). Variation in environmental factors can lead to differences in demographic traits of fishes on scales from tens to thousands of kilometres (e.g. recruitment and growth in Atlantic herring Clupea harengus, Iles \& Sinclair 1982). Variables such as water temperature, turbulence, and wind speed influence the relationship between maternal condition and level of recruitment in Atlantic cod Gadus morhua (Marshall et al. 2000).

Despite the widely recognized roles of the environment and maternal effects on various measures of ELH traits, few studies have attempted to evaluate the interactions between these sources of phenotypic variation. The environment can influence the expression of variation in ELH traits arising from maternal variation in a number of ways: the environment influences female condition or physiology during oogenesis, which then influences propagule condition; females may allocate resources to their offspring according to environmental conditions; maternally mediated offspring traits interact with the offspring's environment after liberation from the female.

An interaction between maternal effects and the general environment may better explain the commonly observed variation in growth rates of young fish and other ELH traits at a range of spatial scales (e.g. Iles \& Sinclair 1982, Sogard \& Able 1992). The goal of this study was to examine the relative contributions of female and environment to offspring variation by assessing the degree of maternal influences on variation in offspring traits in fish from 2 geographically close, but contrasting environments.

\section{MATERIALS AND METHODS}

Study species. Atlantic tomcod Microgadus tomcod is an abundant, bottom-dwelling gadid that inhabits freshwater, estuaries, and salt marshes in the NE Atlantic Ocean, USA and Canada. They are small fish (up to $380 \mathrm{~mm}$ TL) and short-lived (up to $4 \mathrm{yr}$ ) compared to gadids of commercial importance (Stewart \& Auster 1987). Tomcod spend most of their lives in their natal estuaries (Bigelow \& Schroeder 1953), and are capable of reproducing within their first year. They are determinate spawners, releasing negatively buoyant eggs in winter (Dec-Feb), a strategy that subjects eggs and young larvae to temperatures close to $0^{\circ} \mathrm{C}$, and avoids competition for food with larvae of other species (McLaren et al. 1988).

Study sites. We collected broodstock from 2 locations (in New York, USA) with contrasting environmental and physical features. These locations, Shinnecock Bay (SB) and the Hudson River (HR), are at the southern extreme of the species' reproductive range (Stewart \& Auster 1987), and are approximately $135 \mathrm{~km}$ apart. SB is a highly productive, shallow barrier beach and lagoon estuary with salt marshes. It is connected to the ocean through a narrow tidal inlet. The bay covers an area of $39 \mathrm{~km}^{2}$, receives little freshwater inflow (average salinity $30 \mathrm{ppt}$, USACE 2004), and has an average depth of $2 \mathrm{~m}$ (maximum depth of $4 \mathrm{~m}$ ). Water temperatures in SB range from 4 to $20^{\circ} \mathrm{C}$ (Fig. 1) and current flows average $0.2 \mathrm{~m} \mathrm{~s}^{-1}$. Dissolved oxygen (DO) and light levels are relatively high (average DO $9 \mathrm{mg}$ $\mathrm{l}^{-1}$; Secchi depth $2.4 \mathrm{~m}$, USACE 2004). In contrast, HR is a tidal river with variable physical conditions along its length, including forested mountains at its headwaters and heavy urbanization in the New York City region. It has a watershed $\left(34700 \mathrm{~km}^{2}\right) 1000$ times larger than that of $\mathrm{SB}$, and major freshwater influxes fed by mountain lakes and streams, resulting in high water flows (up to $509 \mathrm{~m}^{3} \mathrm{~s}^{-1}$ ). Water temperature in $\mathrm{HR}$ ranges from 0 to $27^{\circ} \mathrm{C}$ (Fig. 1) and turbidity is high relative to $\mathrm{SB}$. More than $300 \mathrm{~km}$ of the river is designated as a US federal Superfund site due to hazardous waste spills from industrial developments (www.epa.gov).

Broodstock and experimental design. Adults were collected in December 2004 by pound net in SB and trap net in HR, then transported to the NOAA Fisheries Service Howard Marine Sciences Laboratory, Highlands, New Jersey, USA. Males and females were stocked separately in circular tanks $(1.8 \mathrm{~m}$ diam.) and supplied with flow-through water from Sandy Hook Bay, New Jersey, at ambient temperature ( 4 to $5^{\circ} \mathrm{C}$ ) and salinity ( 22 to $24 \mathrm{ppt}$ ). Fish were fed a slurry of squid, euphausids and adult Artemia (ratio $3: 1: 1)$ every other day, to satiation. Female ripeness was checked every morning and eggs were stripped from flowing females (i.e. those that freely exuded eggs when light pressure was applied to the abdomen). Eggs from each of 14 HR females were fertilised with milt from one of 14 HR males, creating 14 full-sibling families. Eggs from each of 9 SB females 


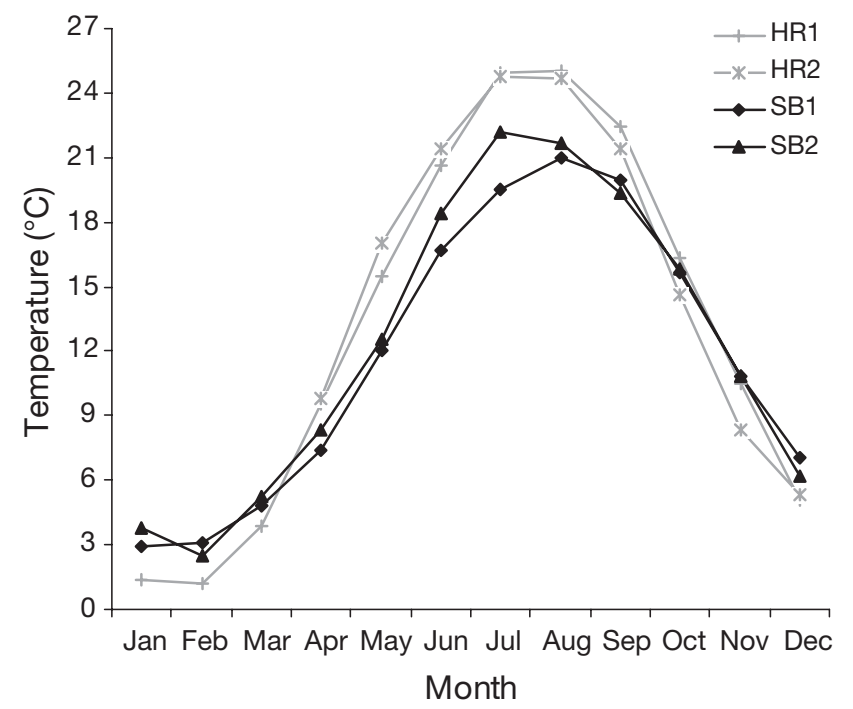

Fig. 1. Mean monthly temperature from Hudson River (HR) and Shinnecock Bay (SB) between 1998 and 2002, except SB2 (1977 to 2004). HR1 is Poughkeepsie, $41^{\circ} 42^{\prime} 11^{\prime \prime} \mathrm{N}, 73^{\circ} 56^{\prime} 28^{\prime \prime} \mathrm{W}$ and HR2 is Tivoli South Bay (cdmo.baruch.sc.edu), 42 $01^{\circ} 37^{\prime \prime} \mathrm{N}, 73^{\circ} 55^{\prime} 33^{\prime \prime} \mathrm{W}$. HR sites are $\sim 60 \mathrm{~km}$ upstream from where the adult tomcod spawn and eggs develop, however, there is a strong positive relationship between the temperature at the spawning site and HR2 $\left(\mathrm{r}^{2}=0.97\right.$, Wells \& Young 1992). Data for SB1 (www.lishore.org), and SB2 (R. Nuzzi unpubl.) were collected from the bay side of Shinnecock Inlet, Long Island, New York, $40^{\circ} 50^{\prime} \mathrm{N}, 72^{\circ} 28^{\prime} \mathrm{W}$. Temperatures for all sites were recorded $0.5 \mathrm{~m}$ below the surface, daily temperature means were calculated from data collected every $3 \mathrm{~min}$, and monthly means were calculated over $4 \mathrm{yr}$

were fertilised with milt from one of 5 males (2 of 5 males were used for single crosses and 3 were used for crosses with multiple females), producing 9 families with unique maternal heritage (Table 1).

After eggs were stripped, females were weighed, measured (total length, TL [mm]), and sacrificed. Their ovaries were removed and weighed, and 3 subsections were weighed and preserved in modified Gilson's fluid (100 ml 60\% alcohol, $800 \mathrm{ml}$ water, $15 \mathrm{ml}$ $80 \%$ nitric acid, $18 \mathrm{ml}$ glacial acetic acid, $20 \mathrm{~g}$ mercuric chloride, Bagenal \& Braun 1978). Two hours after fertilisation, a sample of approximately 50 eggs was taken and preserved in 5\% seawater-buffered formalin for later egg size measurement.

Within $48 \mathrm{~h}$ of fertilisation, 3 replicates of 100 eggs from each cross were allocated to beakers filled to $80 \mathrm{ml}$ with 5 ppt salt-water (mixed from Coral Sea ${ }^{\circledR}$ synthetic sea salt and de-ionised water). Beakers were maintained in a refrigerator at $4^{\circ} \mathrm{C}$ and a $10: 14 \mathrm{~h}$ light:dark cycle, and water was changed daily until all embryos either hatched or died. We checked daily for hatchlings, which were preserved in $5 \%$ seawaterbuffered formalin. On the modal hatch day, 10 live hatchlings from each replicate were placed into a $100 \mathrm{ml}$ beaker to assess larval survival time in the absence of food.

Trait measurement. Egg weight and number: Female fecundity was calculated from 3 ovarian subsamples taken before fertilisation. Approximate egg weight $\left(E_{\mathrm{w}}\right)$ per female was calculated following:

$$
E_{\mathrm{w}}=\mu\left(S_{\mathrm{w} 1} / n_{1+S_{\mathrm{w} 2}} / n_{2}+S_{\mathrm{w} 3} / n_{3}\right)
$$

where $s_{\mathrm{w}}$ is the ovary sub-sample weight, $n$ is the number of eggs in each of the ovary samples, and $\mu$ is the mean. From this, the egg number $(E)$ for each female was estimated from:

$$
E=O_{\mathrm{w}} / E_{\mathrm{w}}
$$

where $O_{\mathrm{w}}$ is total ovary weight for each female.

Gonado-somatic index (GSI) was calculated as:

$$
\mathrm{GSI}=\left(O_{\mathrm{w}} / \mathrm{B}_{\mathrm{w}}\right) \times 100
$$

where $B_{\mathrm{w}}$ is body weight of the female.

Egg size: Images of 30 fertilized eggs from each female (HR: $\mathrm{n}=14$ females, SB: $\mathrm{n}=9$ females) were captured with a Zeiss image analysis package (AxioCam, Zeiss). Maximum egg length and height (external edge of chorion) were measured using UTHSCSA Image Tool graphics package (University of Texas). The eggs were approximately spherical in shape, so the mean of these 2 measurements was used to estimate egg diameter.

Hatchlings: Standard length (SL) and yolk-sac length and height of newly hatched larvae were measured from images of lateral views of preserved hatchlings sampled on or near the modal day of the hatch

Table 1. Microgadus tomcod. Details of crosses. HR = Hudson River, $\mathrm{SB}=$ Shinnecock Bay. Only 5 males were available from $\mathrm{SB} ; 2$ of these (males 2 and 4 ) were crossed once each, with females 4 and 7 , respectively, while remaining males

(1, 3 and 5) were mated with 2 or 3 different SB females

\begin{tabular}{|lcccc|}
\hline Cross & HR female & HR male & SB female & SB male \\
\hline 1 & 1 & 1 & 1 & 1 \\
2 & 2 & 2 & 2 & 1 \\
3 & 3 & 3 & 3 & 1 \\
4 & 4 & 4 & 4 & 2 \\
5 & 5 & 5 & 5 & 3 \\
6 & 6 & 6 & 6 & 3 \\
7 & 7 & 7 & 7 & 4 \\
8 & 8 & 8 & 8 & 5 \\
9 & 9 & 9 & 9 & 5 \\
10 & 10 & 10 & & \\
11 & 11 & 11 & & \\
12 & 12 & 12 & & \\
13 & 13 & 13 & & \\
14 & 14 & 14 & & \\
\end{tabular}


frequency distribution. Images were captured and measured following the methods described above. Yolk volume $(V)$ was approximated by the formula for a prolate spheroid:

$$
V=4 / 3 \pi A B^{2}
$$

where $A$ is yolk length and $B$ is yolk height.

Analysis. Initially, the data were analysed for all individuals by pooling across populations in order to examine trends in female and offspring traits. Then, traits of both the females and their offspring were compared between the 2 source populations. The relationship between ovary and body weight of females from the 2 populations (adjusted for standard length) was compared by ANCOVA. No interaction between population and standard length was found (i.e. there was homogeneity of slopes), so a conventional ANCOVA was used. Differences in offspring traits between populations and among females within populations were tested by MANOVA, with Pillai's trace as the test statistic. In this model, the response variables tested were mean egg diameter, modal time to hatch, mean SL and yolk volume at hatch, and median time to starvation (time to $50 \%$ mortality, 'T $50 \%$ mort') for each replicate within females. Population differences in time to starvation were examined using the Kaplan-Meier survival function of Statistica; all statistical analyses were performed using Statistica (StatSoft).

Table 2. Microgadus tomcod. Correlation coefficient matrix for female traits. GSI: gonado-somatic index, HR: Hudson River, SB: Shinnecock Bay. Bold values: significant correlations at Bonferroni-adjusted $\mathrm{p}<0.003$

\begin{tabular}{|lrlcll|}
\hline Trait & $\begin{array}{c}\text { Egg } \\
\text { size }\end{array}$ & TL & Weight $\begin{array}{c}\text { Ovary GSI } \\
\text { weight }\end{array}$ \\
\hline Pooled $\mathrm{n}=23$ & & & & & \\
TL & 0.05 & & & & \\
Weight & 0.11 & $\mathbf{0 . 9 6}$ & & & \\
Ovary weight & 0.12 & $\mathbf{0 . 8 1}$ & $\mathbf{0 . 8 8}$ & & \\
GSI & 0.07 & 0.36 & 0.41 & $\mathbf{0 . 7 8}$ & \\
Egg number & 0.05 & 0.55 & 0.59 & $\mathbf{0 . 8 7}$ & $\mathbf{0 . 9 0}$ \\
SB females n $=9$ & & & & & \\
TL & -0.36 & & & & \\
Weight & -0.05 & 0.74 & & & \\
Ovary weight & -0.16 & $\mathbf{0 . 9 2}$ & 0.83 & & \\
GSI & -0.22 & 0.69 & 0.18 & 0.69 & \\
Egg number & -0.48 & $\mathbf{0 . 9 3}$ & 0.56 & $\mathbf{0 . 8 7}$ & 0.82 \\
HR females n $=14$ & & & & & \\
TL & 0.15 & & & & \\
Weight & 0.14 & $\mathbf{0 . 9 8}$ & & & \\
Ovary weight & 0.06 & $\mathbf{0 . 9 1}$ & $\mathbf{0 . 9 5}$ & & \\
GSI & -0.14 & 0.51 & 0.55 & 0.77 & \\
Egg number & -0.02 & 0.67 & 0.69 & $\mathbf{0 . 8 6}$ & $\mathbf{0 . 8 8}$ \\
\hline
\end{tabular}

\section{RESULTS}

\section{Pooled across locations}

Adult female tomcod ovary weight increased with body weight and TL, and egg number increased with ovary weight when adult traits were pooled across locations (Table 2). When offspring traits were included with female traits, female weight was predictive of ovary weight and gonado-somatic index (GSI) when the data were pooled across locations (multiple regression, $\left.\mathrm{R}=0.99, F_{7,15}=93.9, \mathrm{p}<0.00005\right)$, but not offspring traits of SL, yolk volume, starvation resistance and time to hatching.

\section{Population differences in female traits}

Adult female traits differed between the HR and SB populations (Table 2, Fig. 2). Ovary weight and egg number of SB females, and ovary weight and body weight of HR females, increased with female length
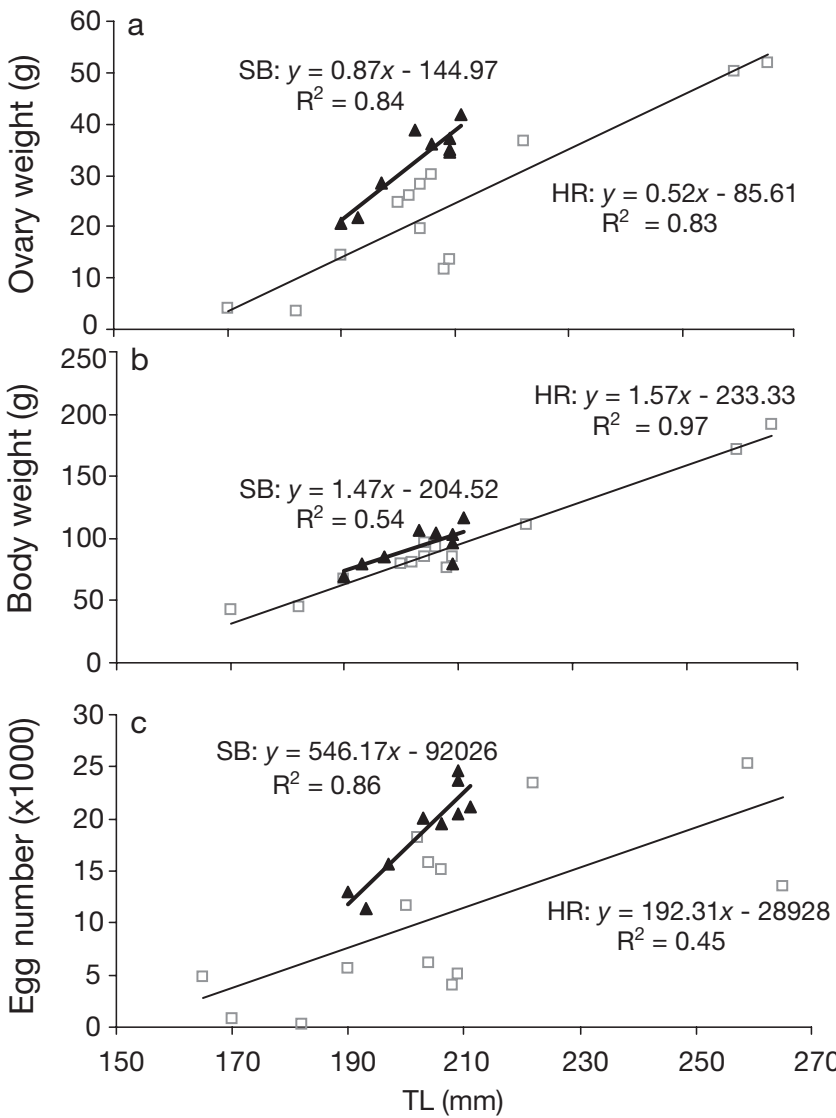

Fig. 2. Microgadus tomcod. Relationship between total length (TL) and (a) ovary weight, (b) body weight, and (c) egg number of females from 2 locations, ( $\square$ ) HR, Hudson River and (ム) SB, Shinnecock Bay 
Table 3. Microgadus tomcod. Evaluation of the effects of source population (Pop: Hudson River or Shinnecock Bay) on female body weight, ovary weight and GSI between populations using female TL as the covariate in an ANCOVA; Type III SS. Bold values: significant differences,

$$
\mathrm{p}<0.05
$$

\begin{tabular}{|lrrrc|}
\hline Source & df & MS & $F$ & $\mathrm{p}$ \\
\hline Body weight & & & & \\
Female TL & 1 & 24455 & 242.73 & $<\mathbf{0 . 0 0 0 1}$ \\
Pop & 1 & 274.64 & 2.72 & 0.11 \\
Error & 20 & 100.75 & & \\
Ovary weight & & & & \\
Female TL & 1 & 2833.86 & 82.73 & $\mathbf{< . 0 0 0 1}$ \\
Pop & 1 & 677.46 & 19.78 & $\mathbf{0 . 0 0 0 2}$ \\
Error & 20 & 34.25 & & \\
GSI & & & & \\
Female TL & 1 & 309.94 & 7.074 & $\mathbf{0 . 0 1 5}$ \\
Pop & 1 & 793.65 & 18.12 & $\mathbf{0 . 0 0 0 3}$ \\
Error & 20 & 43.81 & & \\
& & & & \\
\hline
\end{tabular}

(Table 2, Fig. 2). Females from SB had higher ovary weights (Fig. 2a) and GSI relative to body length (Table 3), and produced more eggs (Fig. 2c, 3a) than females from HR. Female body weight (with length as a covariate) did not differ between HR and SB populations (Fig. 2b, Table 3). No female trait (size, weight) was correlated with offspring traits when the populations were analyzed separately (at Bonferronicorrected significance, $\mathrm{p}<0.003$ ).

\section{Population differences in offspring traits}

When HR and SB offspring were raised in a common environment, offspring traits differed between the populations (Pillai's trace, $F_{2,45}=5.6 \times 10^{14}, \mathrm{p}<0.0001$ ), and between females within populations (Pillai's trace, $\left.F_{42,92}=16.4 \times 10^{14}, \mathrm{p}<0.0001\right)$. Within each population, offspring traits were not correlated (at Bonferronicorrected significance, $\mathrm{p}=0.0004)$.
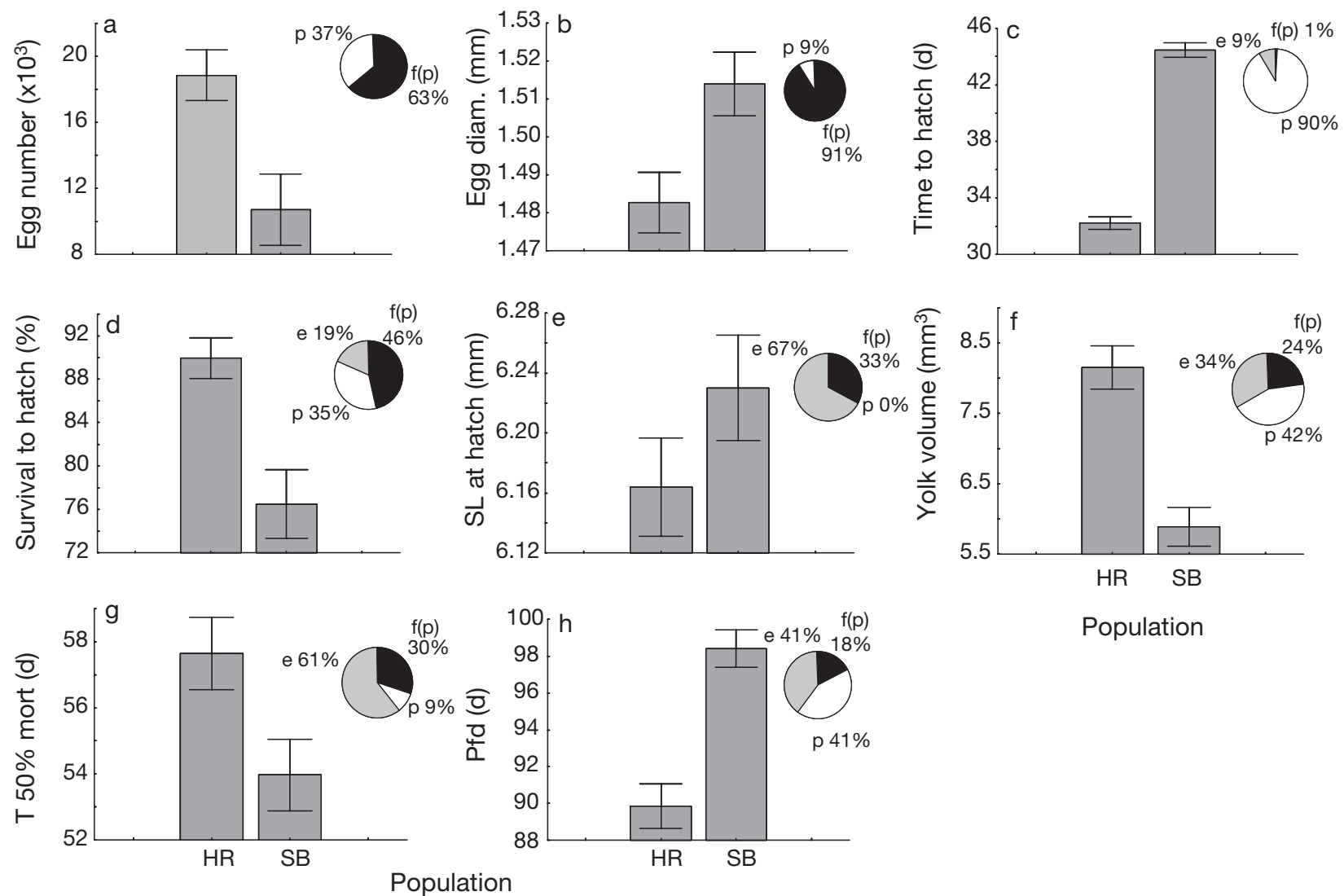

Population

Fig. 3. Microgadus tomcod. Mean offspring traits of Hudson River (HR, $n=14)$ and Shinnecock Bay $(S B, n=9)$ tomcod, maintained by female $(\mathrm{a}, \mathrm{b})$ or maternal sibship $(\mathrm{c}-\mathrm{h})$ in a common environment at $4^{\circ} \mathrm{C}$. Error bars: SE. (a) egg number per female; (b) egg diameter at fertilisation; (c) time to modal day of hatching, measured from day of fertilisation; (d) survival to hatch; (e) standard length (SL) of hatchlings; (f) yolk volume of hatchlings; (g) time to $50 \%$ mortality after hatching in the absence of food; (h) post-fertilisation duration (pfd) from fertilisation to starvation. Pie charts: percentage of variance attributable to population (p), female nested within population $(\mathrm{f}(\mathrm{p}))$, and error $(\mathrm{e})$ 
Egg traits

Mean egg diameter at fertilisation was larger for SB than HR offspring, although only $9 \%$ of the total variance was due to population source (Fig. 3b, Table 4). Over $90 \%$ of the variance in egg size was due to

Table 4. Microgadus tomcod. Evaluation of the effects of source population (Pop) and female nested within source population ( $\mathrm{F}(\mathrm{pop}))$ ), on offspring traits from Shinnecock Bay and Hudson River. Results are for separate univariate ANOVAs for each response variable

\begin{tabular}{|c|c|c|c|c|}
\hline Trait and source & df & MS & $F$ & $\mathrm{p}$ \\
\hline \multicolumn{5}{|l|}{ Egg size } \\
\hline $\mathrm{F}(\mathrm{Pop})$ & 21 & 0.008 & $4.75 \times 10^{14}$ & $<0.01$ \\
\hline Pop & 1 & 0.016 & $1.01 \times 10^{15}$ & $<0.01$ \\
\hline Error & 46 & & & \\
\hline \multicolumn{5}{|l|}{ Time to hatch } \\
\hline F(Pop) & 21 & 10.08 & 1.4088 & 0.165 \\
\hline Pop & 1 & 2414.95 & 239.4730 & $<0.0001$ \\
\hline Error & 45 & 7.16 & & \\
\hline \multicolumn{5}{|l|}{ Survival to hatch } \\
\hline $\mathrm{F}(\mathrm{Pop})$ & 21 & 0.13 & 8.37348 & $<0.000$ \\
\hline Pop & 1 & 1.11 & 8.24293 & 0.009 \\
\hline Error & 45 & 0.02 & & \\
\hline \multicolumn{5}{|l|}{ SL } \\
\hline F(Pop) & 21 & 0.07 & 2.46 & $<0.005$ \\
\hline Pop & 1 & 0.07 & 2.59 & 0.114 \\
\hline Error & 46 & 0.03 & & \\
\hline \multicolumn{5}{|l|}{ Yolk volume } \\
\hline F(Pop) & 21 & 5.97 & 3.083 & $<0.001$ \\
\hline Pop & 1 & 84.55 & 43.636 & $<0.0001$ \\
\hline Error & 46 & 1.94 & & \\
\hline \multicolumn{5}{|l|}{ T $50 \%$ mort } \\
\hline F(Pop) & 21 & 72.9 & 2.4923 & 0.004 \\
\hline Pop & 1 & 222.6 & 3.0548 & 0.09 \\
\hline Error & 45 & 29.2 & & \\
\hline
\end{tabular}

females within populations, and there was more variation within the HR population than SB (coefficient of variation $[\mathrm{CV}]: \mathrm{HR}=5.3, \mathrm{SB}=4.1$ ). Modal hatch-date was $25 \%$ earlier for HR than SB offspring when pooled across families (32 vs. $45 \mathrm{~d}$ after fertilisation [daf] respectively, $F_{1,46}=244, \mathrm{p}<0.0001$ ) (Fig. 4a). When population and female effects were considered concurrently, population differences accounted for $90 \%$ of the variation measured in time to hatch (Fig. 3c). HR offspring not only hatched earlier than SB offspring (mean and modal), but the variance in hatch time was substantially less (range 30 d, c.f. 40 d), resulting in a higher hatch rate per day for HR (Fig. 4). There was significant variation in hatch times between females within HR, but not within SB (Tukey's test, $\mathrm{p}<0.05$ ) (Fig. $4 \mathrm{~b}$ ), and only $1 \%$ of the variance in time to modal hatchling was attributed to females nested within populations. HR eggs had better survival to hatch (Fig. 3d, Table 4$)$, though a large proportion $(46.5 \%)$ of the variance in this trait was attributable to females within population.

\section{Larval traits}

The mean size (SL) of larvae at hatching did not differ between offspring from SB and HR, but did differ between females within populations (Table 4, Fig. 3e). Almost one-third of the variance in this trait was attributable to females within populations, two-thirds to within female variance (error) and only a nominal amount $(<1 \%)$ was due to population differences (Fig. 3e). Newly hatched larvae from HR had larger yolk-sacs than larvae from SB (Fig. 3f, Table 4). Approximately $42 \%$ of the variance in yolk-sac volume was due to differences between populations, and one
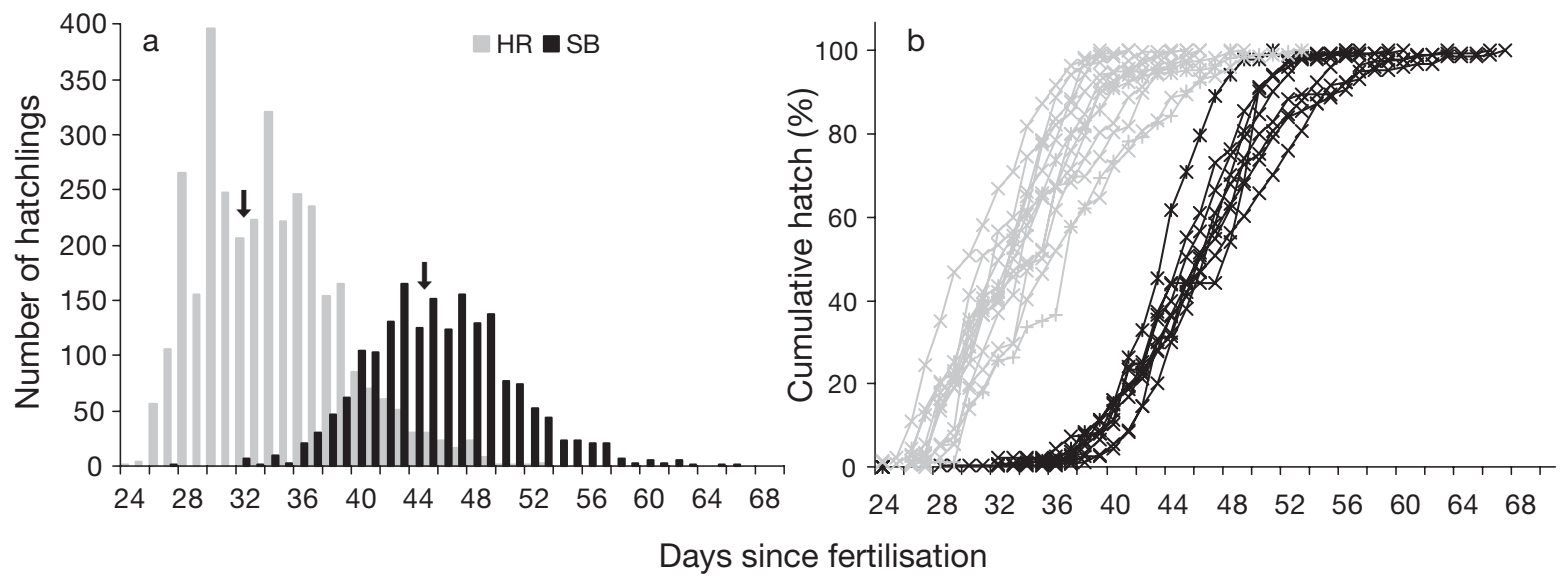

Fig. 4. Microgadus tomcod. (a) Hatch-frequency distribution of all hatchlings from Hudson River (HR) and Shinnecock Bay (SB). Arrows indicate the mean of modal days to hatch for each population. (b) Cumulative frequency distribution of hatching of offspring from each female 

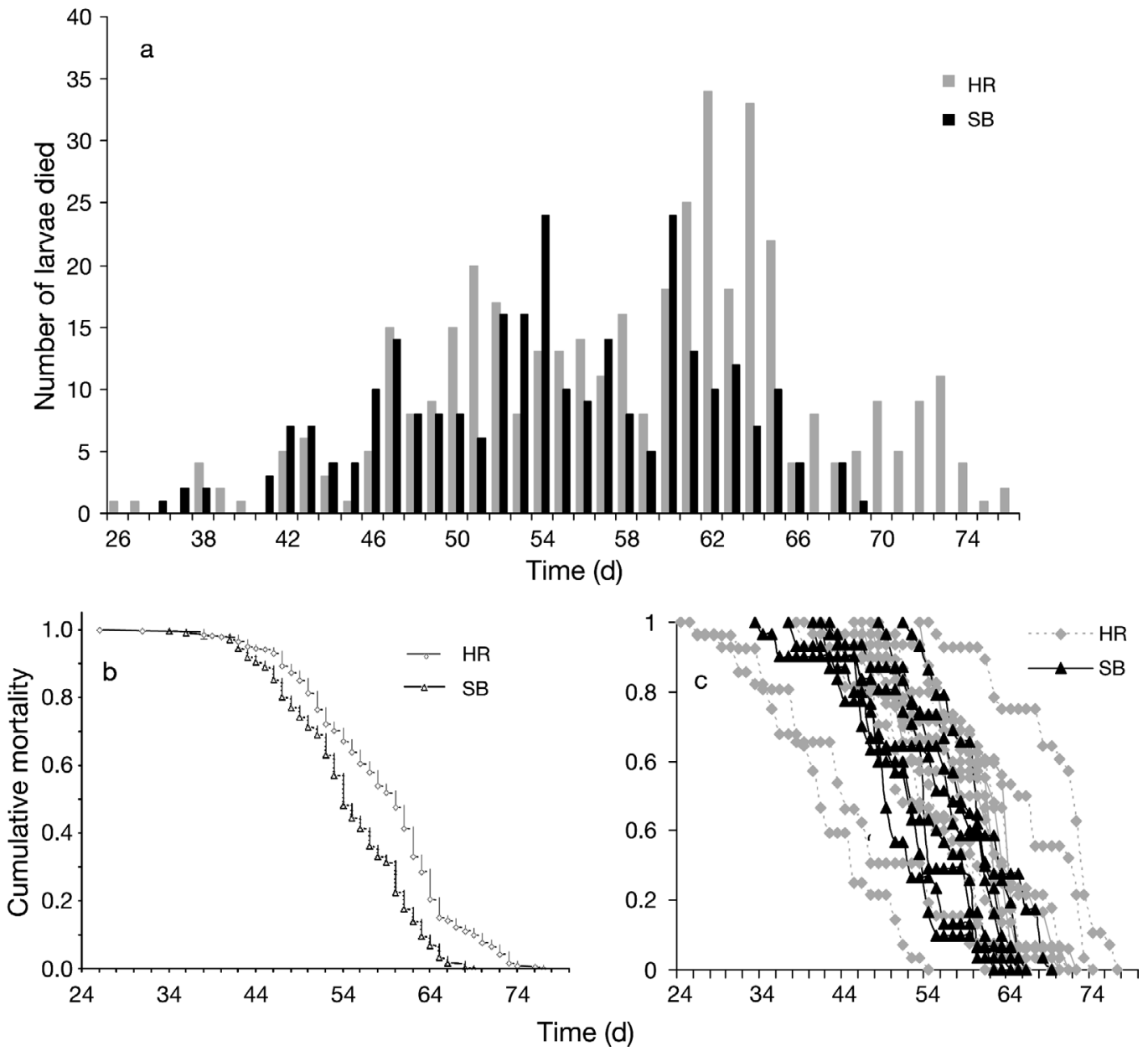

Fig. 5. Microgadus tomcod. Time to mortality of unfed larvae from Hudson River (HR) and Shinnecock Bay (SB), measured from hatching. (a) Larvae pooled across females within populations, (b) cumulative mortality curves (Kaplan-Meier estimates) of larvae, (c) cumulative mortality of larvae pooled by family, HR: $\mathrm{n}=14, \mathrm{SB}: \mathrm{n}=9$

quarter was due to females within population (Fig. 3f, Table 4).

Time to death without exogenous feeding was estimated as a proxy for maternal allocation of endogenous resources. Measured from hatching, HR larvae survived longer in the absence of food than SB larvae (mean of T $50 \%$ mort, p < 0.09) (Fig. 3g); (cumulative mortality, Cox's F-test, $F_{542,816}=1.78, \mathrm{p}<0.00001$ ) (Fig. 5b). However, it is noteworthy that the first individual larvae to die from starvation were from $\mathrm{HR}_{\text {; }}$ deaths of offspring from HR were spread over $52 \mathrm{~d}$, commencing after $26 \mathrm{~d}$ without food, and deaths of offspring from SB were spread over $36 \mathrm{~d}$, commencing after $34 \mathrm{~d}$ without food (Fig. 5a,c). There were also significant differences among females within each population in the survival time of starved offspring (SB: $\chi^{2}=61.03, \mathrm{df}=9, \mathrm{p}<0.00001$; HR: $\chi^{2}=87.19$, df $=10$, $\mathrm{p}<0.00001$ ). To incorporate the observed differences between populations in time to hatching (modal day to hatch, Fig. 3c) into the post-hatching survival time
( $\mathrm{T} 50 \%$ mort), we summed the 2 intervals to compute a 'post-fertilisation time to starvation' (pfs). This broader measure of the subsistence of offspring on endogenous reserves shows Shinnecock Bay individuals survive significantly longer in the absence of exogenous food (Fig. 3h), and source difference accounted for $41 \%$ of the variance in this trait.

\section{Female size and offspring traits}

Female size did not predict egg diameter, egg weight or larval size when these traits were ranked relative to each other on an unweighted ordinal scale (Table 5). No relationships between female and offspring traits were significant at the Bonferroni-corrected significance $\mathrm{p}<0.003$, but ranked egg weight and standard length at hatching were correlated to yolk volume for SB fish and time to hatching for HR fish at $\mathrm{p}<0.05$ (Table 5). 
Table 5. Microgadus tomcod. Spearman's Rank correlations (R) of female and offspring traits. Offspring traits are the average of each replicate per female. ${ }^{*}$ Significant at $p<0.05$, no results significant at Bonferroni-corrected $\mathrm{p}<0.003 . \mathrm{T}=$ time to event

\begin{tabular}{|lrrrrr|}
\hline & $\begin{array}{c}\text { Female } \\
\text { TL }\end{array}$ & $\begin{array}{c}\text { Egg } \\
\text { weight }\end{array}$ & $\begin{array}{c}\text { SL } \\
\text { hatch }\end{array}$ & $\begin{array}{c}\text { Yolk } \\
\text { vol. }\end{array}$ & $\begin{array}{c}\text { T 50\% } \\
\text { mort }\end{array}$ \\
\hline SB n = 9 & & & & & \\
Egg weight & -0.02 & & & & \\
SL hatch & -0.31 & 0.27 & & & \\
Yolk volume & -0.32 & $0.67^{*}$ & $0.77^{*}$ & & \\
T 50\% mort & -0.31 & 0.39 & 0.63 & 0.52 & \\
T modal hatch & -0.12 & 0.25 & -0.52 & -0.23 & -0.54 \\
HR n = 14 & & & & & \\
Egg weight & -0.12 & & & & \\
SL hatch & 0.39 & -0.15 & & & \\
Yolk volume & -0.15 & 0.11 & -0.29 & & \\
T 50\% mort & -0.21 & 0.04 & 0.08 & 0.13 & \\
T modal hatch & 0.39 & $-0.67^{*}$ & $0.61^{*}$ & -0.35 & -0.20 \\
& & & & & \\
\hline
\end{tabular}

\section{DISCUSSION}

The quality of tomcod eggs and yolk-sac larvae differed between Shinnecock Bay (SB) and Hudson River (HR) populations when incubated in a common environment. Eggs of SB females were larger in diameter, and their larvae had smaller yolk reserves at hatch, took longer to hatch, and were less resistant to starvation than HR offspring. Larval length at hatching was not different between the 2 populations. Population effects were greater than maternal effects for time to hatch, size of yolk at hatch, and post-fertilisation time to starvation without food. Maternal effects accounted for more variance in egg diameter, number and survival, size at hatching and post-hatching survival without food. One of the possible explanations for these patterns of variation in offspring traits is related to a trade-off between time to hatch and quality at hatch for tomcod populations from geographically close but contrasting environments. The observed variation was most likely caused by modification of maternally derived traits by environmental factors characteristic of the source environments.

\section{Time to hatch versus quality at hatch}

There was a possible trade-off between time to hatch and quality at hatch of offspring, reflecting 2 strategies in egg development for tomcod from HR and SB. HR offspring hatched sooner and the hatchlings had more yolk than SB offspring (Fig. 6). While the quantity or quality of yolk reserves at hatch is generally linked to maternal endowment (e.g. Kerrigan 1997), yolk is depleted during embryogenesis and consequently affected by incubation time. Given that there was no difference in size at hatching between the 2 populations, it appears that HR embryos developed faster to reach hatching size. Yolk quantity at hatching is therefore a result of the initial allocation, reduced by the embryonic metabolic rate and the duration of time before hatching. The shortened and more variable embryonic period in HR offspring may be a strategy to minimise exposure to the highly contaminated sediments in the region, to reduce risk of being washed downstream in fast-moving water flows, or an adaptation to the highly variable and unpredictable environment of the Hudson River.

Population differences in egg diameter, yolk size at hatching and time to hatch did not result in differences in larval length at hatching. While we observed that the HR and SB populations had different egg develop-

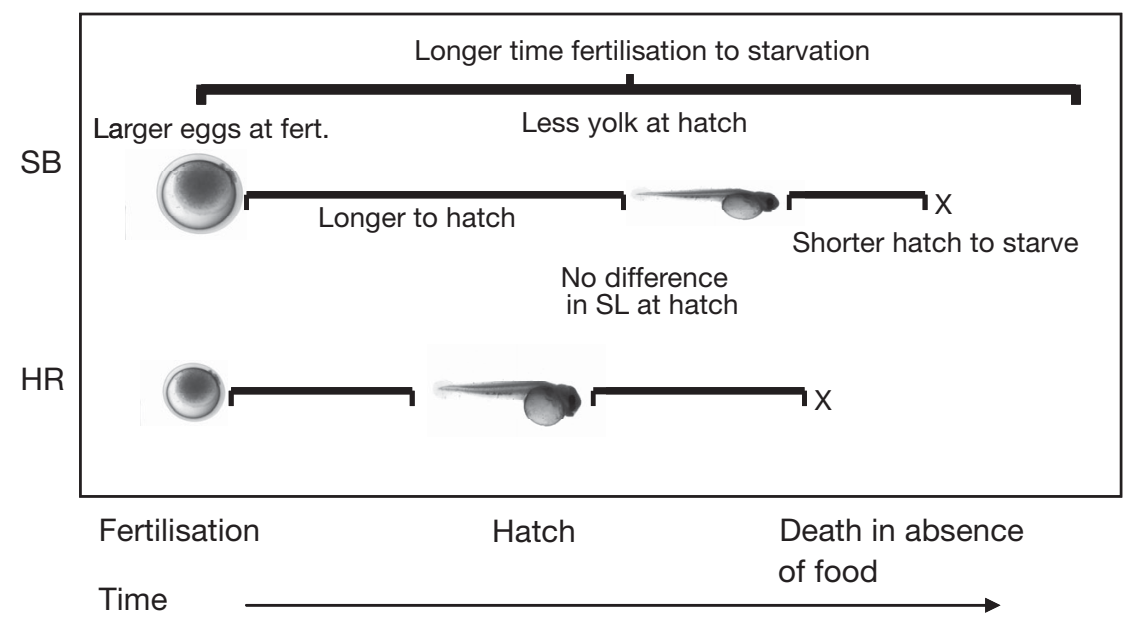

Fig. 6. Microgadus tomcod. Summary of egg and larval development over time for Hudson River (HR) and Shinnecock Bay (SB) fish 
ment rates that influenced age thresholds, they did not ultimately change the trajectory for size at hatching. Size at hatching may be a key trait that is subjected to relatively intense stabilizing selection. Hatching and metamorphosis are generally determined by the size rather than the age of the organism, and size at these life-stage transitions is relatively inflexible even when the organism is subjected to variable environmental conditions (e.g. Platichthys stellatus, Policansky 1983; Pseudopleuronectes americanus, Chambers \& Leggett 1996; Amphiprion melanopus Green \& McCormick 2005). Egg developmental strategies differed between 2 locations, and yolk quantity may reflect female and environmental qualities.

\section{Maternal effects and source population}

Population differences in reproductive and offspring traits may reflect different degrees of maternal effects operating in the 2 source populations. While offspring traits were not linearly related to female traits within or between the populations, maternal effects accounted for more variance than population source in egg diameter, number and survival, size at hatching and posthatching survival without food.

Reproductive traits differed in females from SB and HR populations. SB females had heavier ovaries than HR females for a given fish length. Egg number increased with ovary weight and GSI in HR females, but not SB females. It is unusual that female size and weight were not correlated with offspring traits for either population or when the populations were combined, as female-offspring traits are frequently correlated in fish (e.g. Keckeis et al. 2000, Trippel \& Neil 2004), including tomcod (McLaren et al. 1988). The absence of any detectable correlation between female attributes and offspring traits is possibly a result of the small number of females used in our study. Nevertheless, female identity was an important component of variance in our study, accounting for a level of trait variance comparable to that in other studies (35-71\%, Chambers \& Leggett 1996).

Size of yolk or oil globule at hatching, and posthatching survival without food are common measures of maternal provisioning (e.g. Kerrigan 1997, Chambers et al. 1989). In our study, the population source difference in embryonic duration resulted in greater yolk depletion in SB embryos by hatching. As a consequence, starvation resistance was lower in SB offspring when quantified from hatching onward, but the overall duration of time to starvation was longer when measured from fertilisation. Therefore time to mortality, measured from hatching, is a metric of potential starvation resistance, but not necessarily of maternal pro- visioning. Similarly, longer incubation time for SB eggs was coupled with depletion of yolk reserves available at hatching. Consequently, yolk size at hatching does not necessarily reflect maternal provisioning. SB offspring actually survived longer without feeding when measured from fertilisation to starvation, which better represents the total time offspring subsisted on maternally allocated endogenous reserves. Embryo and larval development are dynamic processes, and snapshot measurements of trait quality may not be a true reflection of maternal provisioning, which incorporates changes over time and may reflect habitat quality.

\section{Environmental differences}

Overall, there were small but significant differences in the reproductive, egg allocation and provisioning strategies between females from the 2 populations. These differences in tomcod ELH traits may be influenced by environmental differences between the 2 habitats. Tomcod tend to spawn in their natal estuaries (Bigelow \& Schroeder 1953), therefore trait differences may be related to either adaptation to local physical environment, to genetic divergence in the populations due to reproductive isolation, or both. Geographic divergence in life history traits occurs in many taxa (e.g. frogs, Laugen et al. 2003; seed beetles, Stillwell \& Fox 2005) and has been demonstrated in response to single environmental variables. Similar latitude and close proximity of HR and SB would notionally expose resident tomcod to similar environmental regimes, however small-scale differences in environmental parameters or habitat could influence reproductive and ELH traits.

The physical environment of HR was more spatially and temporally variable than SB. HR water temperatures are warmer in summer (May to September) and cooler in winter (December to March) than than those of SB. Salinities in the expanse of the HR and lower reaches of the estuary are consistently more variable than those of SB. In general, HR is a highly contaminated and environmentally variable site, and SB is a relatively clean and stable environment. The variability expressed in HR tomcod reproductive and offspring traits may reflect the degree of environmental variability in this system, supporting life history theory predictions that temporal variability in habitat characteristics will increase phenotypic variation and may lead to adaptive changes (McLaren et al. 1988).

Salinity or temperature alone can influence egg size in fishes, and we cannot discount the possibility that the variance noted between populations is in response to such environmental variables. The combination of larger diameter, lighter weight SB eggs may be due to 
higher salinities in SB. An anadromous species, the Arctic char Salvelinus alpinus produces larger diameter eggs at higher salinities (Atse et al. 2002). Conversely, some Baltic Sea fishes (cod Gadus morhua, herring Clupea harengus, sprat Sprattus sprattus, and flounder Platichthys flesus) produce larger eggs at lower salinities (Solemdal 1967). While transplant experiments of female cod from higher salinity ('Baltic' conditions) to lower salinity conditions resulted in an increase in egg diameter, this increase was not equal to the inherent stock differences in egg diameter, suggesting stock-specific adaptation to local environmental conditions (Solemdal 1973). Furthermore, SB salinity infrequently drops below 24 ppt (R. Nuzzi unpubl.), and 24 ppt is near the upper lethal limit for tomcod eggs from both populations in laboratory experiments (R. C. Chambers unpubl.). Groundwater seepage is critical to successful spawning in lacustrine salmonids (Blanchfield \& Ridgway 2005) and successful SB spawning may depend on the availability of habitats with low salinities. If this is the case, then determining the importance of SB salinity to trait quality in situ would require microscale water quality measurements.

Environmental factors external to maternal effects per se can be the dominant controllers of offspring traits. Latitude had a stronger influence on growth rate than maternal effects in a common garden experiment on striped bass (Morone saxatilis) (Brown et al. 1998). Adaptation to local environment, rather than maternal effects, was a dominant source of variation in ELH traits in frogs (Laurila et al. 2002).

\section{CONCLUSIONS}

Our results demonstrated divergence in ELH traits of Atlantic tomcod between 2 populations in close geographic proximity. Maternal effects on offspring traits, while significant, were less important than those attributable to the geographic source population. Moreover, our results emphasize that the magnitude of maternal effects depends on the population source. The 2 populations used here were drawn from environments with different temperatures, salinities, water flow and pollution. These factors, individually or collectively, could influence selection regimes on reproductive and ELH traits, and ultimately the strategies of adult investment in offspring.

Acknowledgements. We thank L. Pandolfo and D. Davis for assistance with husbandry, L. Church and K. Neves for laboratory assistance, and J. Manderson for comments on the manuscript. This research was performed while B.S.G. held a National Research Council Associateship Award at Howard Marine Laboratory, New Jersey, USA.

\section{LITERATURE CITED}

Atse CB, Audet C, de la Noue J (2002) Effects of temperature and salinity on the reproductive success of Arctic char, Salvelinus alpinus (L.): egg composition, milt characteristics and fry survival. Aquac Res 33:299-309

Bagenal TB, Braum E (1978) Eggs and early life history. In: Bagenal TB (ed) Methods for assessment of fish production in fresh waters. Blackwell Scientific, Oxford, p 165-200

Bergenius MAJ, Meekan MG, Robertson DR, McCormick MI (2002) Larval growth predicts the recruitment success of a coral reef fish. Oecologia 131:521-525

Bergenius MAJ, McCormick MI, Meekan MG, Robertson DR (2005) Environmental influences on larval duration, growth and magnitude of settlement of a coral reef fish. Mar Biol 147:291-300

Bigelow HB, Schroeder WC (1953) Fishes of the Gulf of Maine. Fish Bull 53:1-577

Blanchfield PJ, Ridgway MS (2005) The relative influence of breeding competition and habitat quality on female reproductive success in lacustrine brook trout (Salvelinus fontinalis). Can J Fish Aquat Sci 62:2694-2705

Brown JJ, Ehtisham A, Conover DO (1998) Variation in larval growth rate among striped bass stocks from different latitudes. Trans Am Fish Soc 127:598-610

Chambers RC, Leggett WC (1996) Maternal influences on variation in egg sizes in temperate marine fishes. Am Zool 36:180-196

Chambers RC, Leggett WC, Brown JA (1989) Egg size, female effects, and the correlation between early life history traits of capelin, Mallotus villosus: an appraisal at the individual level. Fish Bull 87:515-523

Ferron A, Leggett WC (1994) An appraisal of condition measures for marine fish larvae. Adv Mar Biol 30:217-303

Green BS, Fisher R (2004) Temperature influences swimming speed, growth and larval duration in coral reef fish larvae. J Exp Mar Biol Ecol 299:115-132

Green BS, McCormick MI (1999) Influence of larval feeding history on the body condition of Amphiprion melanopus. J Fish Biol 55:1273-1289

Green BS, McCormick MI (2005) Maternal and paternal effects determine size, growth and performance in larvae of a tropical reef fish. Mar Ecol Prog Ser 289: 263-272

Heath DD, Blouw DM (1998) Are maternal effects in fish adaptive or merely physiological side effects? In: Mouseau TA, Fox CW (eds) Maternal effects as adaptations. Oxford University Press, New York, p 178-201

Hoey A, McCormic MI (2004) Selective predation for low body condition at the larval-juvenile transition of a coral reef fish. Oecologia 139:23-29

Iles TD, Sinclair M (1982) Atlantic herring: stock discreteness and abundance. Science 215:627-633

Keckeis HE, Bauer-Nemeschkai VM, Nemeschkai HL, Kamler E (2000) Effects of female attributes and egg properties on offspring viability in a rheophilic cyprinid Chondrostoma nasus. Can J Fish Aquat Sci 57:789-796

Kerrigan BA (1997) Variability in larval development of a tropical reef fish (Pomacentridae: Pomacentrus amboinensis): the parental legacy. Mar Biol 127:395-402

Laugen AT, Laurila A, Merilä J (2003) Latitudinal and temperature-dependent variation in embryonic development and growth in Rana temporaria. Oecologia 135:548-554

Laurila A, Karttunen S, Merilä J (2002) Adaptive phenotypic plasticity and genetics of larval life histories in two Rana temporaria populations. Evolution 56:617-627

Marshall CT, Yaragina NA, Ådlandsvik B, Dolgov AV (2000) Reconstructing the stock-recruit relationship for Northeast 
Arctic cod using a bioenergetic index of reproductive potential. Can J Fish Aquat Sci 57:2433-2442

Marteinsdottir G, Steinarsson A (1998) Maternal influence on the size and viability of Iceland cod Gadus morhua eggs and larvae. J Fish Biol 52:1241-1258

McLaren JB, Peck TH, Dey WP, Gardinier M (1988) Biology of Atlantic tomcod in the Hudson River estuary. In: Barnthouse LW, Klauda RJ, Vaughan DS, Kendall RL (eds) Science, law and Hudson River power plants. American Fisheries Society Monograph 4. American Fisheries Society, Bethesda, MD, p 102-112

Meekan M, Fortier L (1996) Selection for fast growth during the larval life of Atlantic cod Gadus morhua on the Scotian Shelf. Mar Ecol Prog Ser 137:25-37

Policansky D (1983) Size, age and demography of metamorphosis and sexual maturation in fishes. Am Zool 23:57-63

Sogard SM, Able KW (1992) Growth variation of newly settled winter flounder (Pseudopleuronectes americanus) in New Jersey estuaries as determined by otolith microstructure. Neth J Sea Res 29:163-172

Solemdal P (1967) The effect of salinity on buoyancy, size and development of flounder eggs. Sarsia 29:431-442

Solemdal P (1973) Transfer of Baltic flatfish to a marine environment and the long term effects on reproduction. Oikos 15:268-276

Sponaugle S, Grorud-Colvert K, Pinkard D (2006) Temperature-mediated variation in early life history traits and recruitment success of the coral reef fish Thalassoma bifasciatum in the Florida Keys. Mar Ecol Prog Ser 308:1-15

Editorial responsibility: John Choat (Contributing Editor), Townsville, Queensland, Australia
Steward LL, Auster PJ (1987) Species profile: life histories and environmental requirements of coastal fishes and invertebrates (North Atlantic) - Atlantic tomcod. US Fish Wildl Serv Biol Rep 82 (11.76) US Army Corps of Engineers, TR EL-82-4, p 8

Stillwell RC, Fox CW (2005) Complex patterns of phenotypic plasticity: interactive effects of temperature during rearing and oviposition. Ecology 86:924-934

Trippel EA, Neil SRE (2004) Maternal and seasonal differences in egg sizes and spawning activity of northwest Atlantic haddock (Melanogrammus aeglefinus) in relation to body size and condition. Can J Fish Aquat Sci 61:2097-2110

USACE (US Army Corps of Engineers) (2004) Atlantic coast of Long Island, Fire Island to Montauk Point, New York, Reformulation study. Submerged aquatic vegetation (SAV) bed characterization, US Army Corps of Engineers, New York district, New York

Vigliola L, Meekan MG (2002) Size at hatching and planktonic growth determine post-settlement survivorship of a coral reef fish. Oecologia 131:89-93

Wells AW, Young JR (1992) Long-term variability and predictability of Hudson River physical and chemical characteristics. In: Smith CL (ed) Estuarine research in the 1980's. The Hudson River Environmental Society, 7th Symposium on Hudson River ecology. SUNY Press, New York, p 29-58

Wright PJ, Gibb FM (2005) Selection for birth date in North Sea haddock and its relation to maternal age. J Anim Ecol 74:303-312

Submitted: October 19, 2006; Accepted: February 28, 2007 Proofs received from author(s): August 10, 2007 